\title{
A real pain in the neck: Giant cell arteritis presenting with non-necrotising fasciitis and fever
}

Karen M Dwyer ${ }^{1,2}$, Alex Tai ${ }^{1}$, Paul Smith ${ }^{1}$, Rachelle Buchbinder ${ }^{3}$

1. Epworth HealthCare, Epworth Geelong

2. Deakin University, School of Medicine, Faculty of Health

3. Monash Department of Clinical Epidemiology, Cabrini Institute and Department of Epidemiology and Preventive Medicine, School of Public Health and Preventive Medicine, Monash University

Corresponding author:

Karen M Dwyer

Prof Medicine, Deputy Head, School of Medicine

Faculty of Health

Locked Bag 20000

Geelong, Vic, Australia 3220

Email: karen.dwyer@deakin.edu.au

Ph: +6135227 1421

Word count: 499

Key words: Giant cell arteritis; non-necrotising fasciitis.

Giant cell arteritis (GCA) is the most common primary vasculitis in adults aged over 50 years affecting women more frequently ${ }^{1}$. We present a case in which non-necrotizing fasciitis manifesting as neck pain and fever were the presenting features.

A 95 year old woman with a history of macular degeneration presented with fever, 3 weeks of acute neck pain, headache, night sweats and myalgias. Oral intake was reduced secondary to a "tired jaw". Examination revealed prominent but non-tender pulsatile temporal arteries. Fundoscopy revealed a right swollen optic disc. Investigations were notable for a raised ESR $80 \mathrm{~mm} / \mathrm{h}, \mathrm{CRP} 220 \mathrm{mg} / \mathrm{L}$, white cell count $\left(20 \times 10^{9} / \mathrm{L}\right)$, platelet count and ferritin and hypoalbuminemia.

MRI of the neck showed diffuse enhancement of the posterior fascial planes consistent with fasciitis. No gas locules were identified (Figure 1). There were no obvious abnormalities of the aortic arch or great vessels. Blood cultures were negative. Bilateral temporal artery biopsy confirmed the presence of GCA.

This is the author manuscript accepted for publication and has undergone full peer review but has not been through the copyediting, typesetting, pagination and proofreading process, which may lead to differences between this version and the Version of Record. Please cite this article as doi: 10.1111/imj.14317 
Within one month of treatment with oral prednisolone $40 \mathrm{mg}$ daily her symptoms had resolved and acute phase reactants had normalised. Due to neuropsychiatric side effects from prednisolone subcutaneous weekly tocilizumab $162 \mathrm{mg} / 0.9 \mathrm{~mL}$ was commenced. She remains well living independently and right eye fundoscopy is normal eight months after diagnosis.

GCA typically affects the extracranial branches of the external carotid artery and presents with a wide range of clinical manifestations of which headache is most common ${ }^{2}$. Polymyalgia rheumatic (PMR) can be present in up to $50 \%$ of cases ${ }^{1}$. Although neck pain is common in $\mathrm{PMR}^{1}$, the striking feature in this patient is non-necrotizing fasciitis on MRI. Necrotizing fasciitis due to a bacterial aetiology is a medical emergency and the presence of gas along fascial planes is pathognomonic. Non-necrotizing fasciitis has previously been described associated with systemic inflammatory disorders such as systemic lupus erythematous, Churg-Strauss vasculitis and dermatomyositis ${ }^{3}$. We believe this is the first published description of non-necrotizing fasciitis associated with GCA, likely a manifestation of concurrent PMR. While synovitis, bursitis and tenosynovitis have all been observed in PMR, a single report has documented the presence of fasciitis in the deltoid occurring with subdeltoid bursitis ${ }^{4}$.

Severe ischaemic manifestations of GCA occur not infrequently with jaw claudication in $41 \%$ of patients and permanent visual loss in $12.9 \%^{5}$. An abnormal temporal artery on examination ${ }^{2}$, and the presence of traditional atherosclerotic risk factors ${ }^{5}$, increase the risk of ischemic complications.

Temporal artery biopsy has variable sensitivity $(39 \%-90 \%)$, according to the predominant artery involved, timing in relation to commencement of treatment ${ }^{6}$ and inconsistent gold standards. While advancements in imaging technologies have aided in the diagnosis of GCA (reviewed in ${ }^{6}$ ), we believed it prudent to perform temporal artery biopsy to confirm the diagnosis in this patient before committing her to high dose glucocorticoids.

This case highlights an unusual presentation of GCA in a patient with clinical features and biomarkers suggestive of GCA and PMR. This case adds to the list of systemic inflammatory conditions that need to be considered in the aetiology of non-necrotizing fasciitis. 


\section{Figure legend:}

FIGURE 1. Axial (A) and sagittal (B) fat saturated, contrast enhanced T1 weighted images, demonstrate marked enhancement of the posterior neck, deep cervical fascia (arrows). This corresponds with fascial oedema on sagittal T2 fat saturated images (asterisks). Axial CT images demonstrate no gas within the fascia on soft tissue (D) or lung windows (E). 


\section{References:}

1. Salvarani C, Cantini F, Hunder GG. Polymyalgia rheumatica and giant-cell arteritis. Lancet. 2008;372(9634): 234-245.

2. Gonzalez-Gay MA, Barros S, Lopez-Diaz MJ, Garcia-Porrua C, Sanchez-Andrade A, Llorca J. Giant cell arteritis: disease patterns of clinical presentation in a series of 240 patients. Medicine (Baltimore). 2005;84(5): 269-276.

3. Chaudhry AA, Baker KS, Gould ES, Gupta R. Necrotizing fasciitis and its mimics: what radiologists need to know. AJR Am J Roentgenol. 2015;204(1): 128-139.

4. Rozin AP. US imaging of shoulder fasciitis due to polymyalgia rheumatica. Neth J Med. 2008;66(2): 88.

5. Gonzalez-Gay MA, Pineiro A, Gomez-Gigirey A, et al. Influence of traditional risk factors of atherosclerosis in the development of severe ischemic complications in giant cell arteritis. Medicine (Baltimore). 2004;83(6): 342-347.

6. Ninan JV, Lester S, Hill CL. Giant cell arteritis: beyond temporal artery biopsy and steroids. Intern Med J. 2017;47(11): 1228-1240. 
Giant cell arteritis (GCA) is the most common primary vasculitis in adults aged over 50 years and affects women more frequently. We present a case in which non-necrotising fasciitis manifesting as neck pain, and fever were the presenting features. 

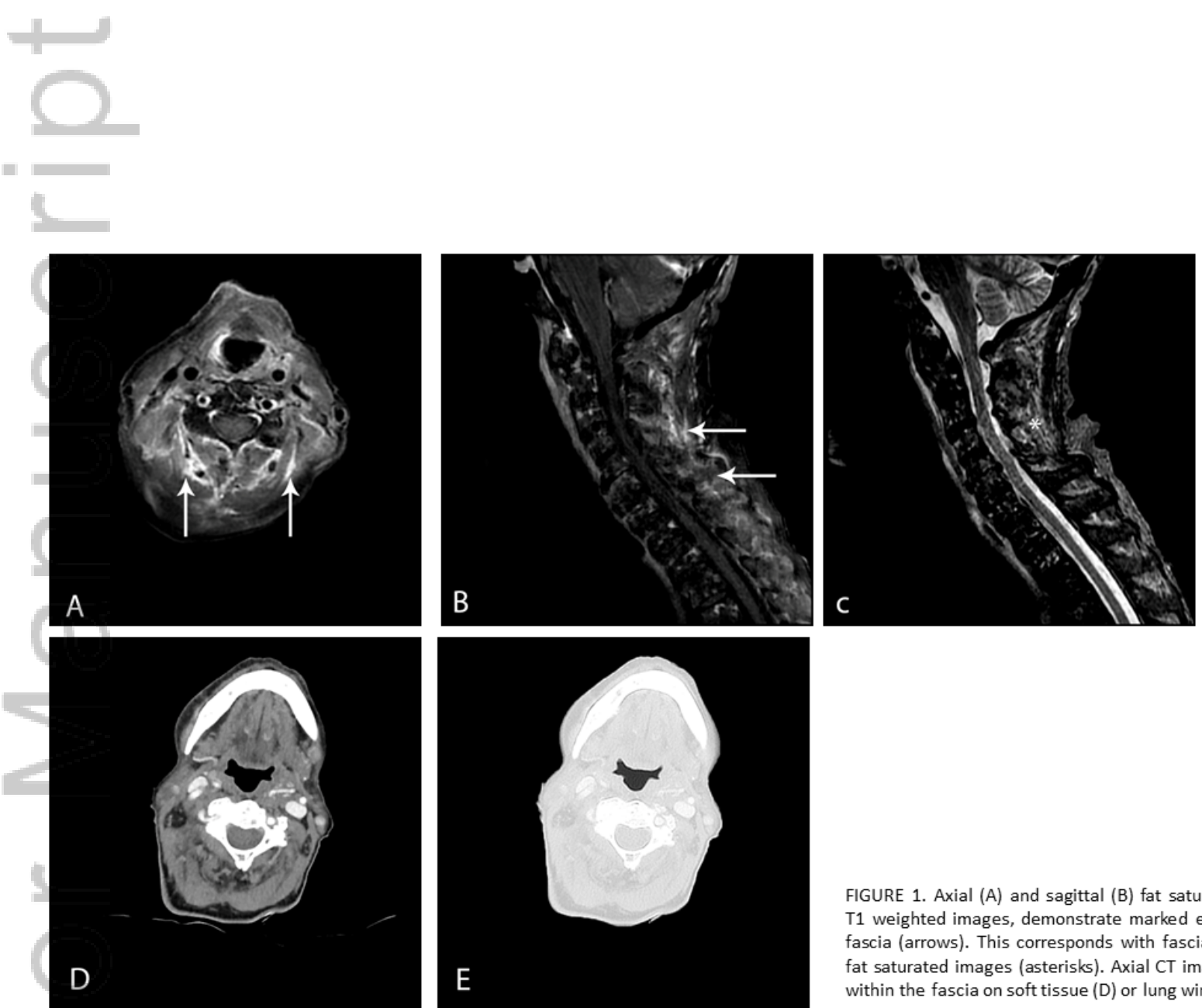

FIGURE 1. Axial (A) and sagittal (B) fat saturated, contrast enhanced

T1 weighted images, demonstrate marked enhancement of the neck fascia (arrows). This corresponds with fascial oedema on sagittal T2 fat saturated images (asterisks). Axial CT images demonstrate no gas D

within the fascia on soft tissue (D) or lung windows (E).

IMJ_14317_Slide1.TIF

This article is protected by copyright. All rights reserved. 


\section{A real pain in the neck: Giant cell arteritis presenting with non-necrotising fasciitis and fever}

Karen M Dwyer ${ }^{1,2}$, Alex Tai ${ }^{1}$, Paul Smith ${ }^{1}$, Rachelle Buchbinder ${ }^{3}$

1. Epworth HealthCare, Epworth Geelong

2. Deakin University, School of Medicine, Faculty of Health

3. Monash Department of Clinical Epidemiology, Cabrini Institute and Department of Epidemiology and Preventive Medicine, School of Public Health and Preventive Medicine, Monash University

Corresponding author:

Karen M Dwyer

Prof Medicine, Deputy Head, School of Medicine

Faculty of Health

Locked Bag 20000

Geelong, Vic, Australia 3220

Email: karen.dwyer@deakin.edu.au

Ph: +6135227 1421

Word count: 499

Key words: Giant cell arteritis; non-necrotising fasciitis. 


\section{University Library}

\section{- M M N E R VA A gateway to Melbourne's research publications}

Minerva Access is the Institutional Repository of The University of Melbourne

Author/s:

Dwyer, KM;Tai, A;Smith, P;Buchbinder, R

Title:

Real pain in the neck: giant cell arteritis presenting with non-necrotising fasciitis and fever

Date:

2019-06-01

Citation:

Dwyer, K. M., Tai, A., Smith, P. \& Buchbinder, R. (2019). Real pain in the neck: giant cell arteritis presenting with non-necrotising fasciitis and fever. INTERNAL MEDICINE JOURNAL, 49 (6), pp.802-804. https://doi.org/10.1111/imj.14317.

Persistent Link:

http://hdl.handle.net/11343/285944 